\title{
THE UTILITY CONCEPT APPLIED TO THE THEORY OF INSURANCE
}

\author{
KARL BORCH, \\ Bergen
}

\section{INTRODUCTION}

1.1. In some recent papers ((I), (2) and (3)) about reinsurance problems I have made extensive use of utility concepts. It has been shown that if a company follows well defined objectives in its reinsurance policy, these objectives can be represented by a utility function which the company seeks to maximise. This formulation of the problem will in general make it possible to determine a unique reinsurance arrangement which is optimal when the company's objectives and external situation are given.

1.2. More than 50 years ago Guldberg (4) wrote (about the probability of ruin): "Wie hoch diese Wahrscheinlichkeit gegriffen werden soll, muss dem subjektiven Ermessen oder von Aussen kommenden Bedingungen überlassen bleiben". This is the traditional approach to reinsurance problems. It does obviously not lead to a determinate solution. Most authors taking this approach conclude their studies by giving a mathematical relation between some measure of "stability", such as the probability of ruin, and some parameter, for instance maximum retention, to which the company can give any value within a certain range. Such studies do usually not state which particular value the company should select for this parameter, i.e. what degree of stability it should settle for. This question is apparently considered as being outside the field of actuarial mathematics.

1.3. The traditional approach implies that the actuary should play a rather modest part in the management of his company. He should provide facts and figures for the use of his superiors, who would make the final decisions on behalf of the company. How these decisions were reached should in principle be no concern of the actuary. This may have been correct in theory $5^{\circ}$ years ago, when 
the famous "hunch" of the born manager was the best available guide for top-level decisions in business. However, the last decades have seen the development of mathematical theories for decision making under uncertainty, and in the light of these theories it appears that the actuary should take a broader view of his duties.

1.4. These mathematical theories can obviously not eliminate the subjective element referred to by Guldberg. However, if one assumes that there is, or at least that there should be some consistency in the various subjective judgements made by an insurance company, fairly extensive mathematical treatment becomes possible. To introduce a utility function which the company seeks to maximise, means only that such consistency requirements are put into mathematical form.

\section{The Theory of Risk}

2.1. To illustrate our point, we shall begin by studying a very simple model. We shall consider an insurance company which holds a portfolio of insurance contracts, all of which will expire before the end of a certain period. We assume that the premium for all contracts has been paid to the company in advance.

The risk situation of the company is then determined by the following two elements:

(i) $F(x)=$ the probability that the total amount of claims being made under the contracts in the portfolio shall not exceed $x$.

(ii) $S=$ the funds which the company holds, and which it can draw upon to pay claims.

At the end of the period the company will hold the amount $y=S-x$, where $y$ is a variate with the probability distribution $G(y)=\mathrm{I}-F(S-y)$ where $-\infty \leq y \leq S$. It is convenient to refer to $G(y)$ as the profit distribution associated with the risk situation $(S, F(x))$.

2.2. In this simple model we can assume that the only thing which matters to the company, is the situation when all contracts have expired. This means that the contract period must be so short that we can ignore the interest earned by the premiums paid in 
advance into the company's funds. In this case all relevant properties of the risk situation are contained in the profit distribution.

In the classical theory of risk attention is focussed on the probability that profit shall be negative at the end of the period, i.e. that the company shall be ruined. This probability is obviously given by:

$$
\int_{S}^{\infty} d F(x)=p(S, F)=\mathrm{I}-F(S)
$$

2.3. The classical theory seems to assume, usually tacitly, that a company should reinsure as little as possible. The reasoning behind this appears to be that reinsurance invariably means a reduction of expected profit. Taking this as a starting point, we can formulate the objectives of the classical theory in an operational manner as follows:

If there are $n$ possible reinsurance arrangements, which will change the risk situation of the company from the initial $(S, F(x))$ to $\left(S_{1}, F_{1}(x)\right) \ldots\left(S_{n}, F_{n}(x)\right)$, the company should select the arrangement $i$ which maximises expected profit

$$
S_{i}-\int_{0}^{\infty} x d F_{i}(x)
$$

subject to the condition

$$
p\left(S_{i}, F_{i}\right) \leq \alpha
$$

where $\alpha$ is the probability which Guldberg considered had to be given from outside.

2.4. This formulation leads to the familiar mathematical problem of maximising a given function when the solution is restrained by an inequality. When $\alpha$ is given, the solution of the problem is straight forward, although the computation involved can present considerable difficulties.

It is, however, evident that this formulation of the reinsurance problem is not very satisfactory. We have taken into account only two properties of the profit distribution, namely its mean, and the part to the left of the origin. It seems unreasonable to assume that an insurance company is completely disinterested in any other property of this distribution, so it is desirable to develop a more general theory. For such a theory it appears that a utility concept, or something equivalent is indispensable. 
2.5. The modern, so-called "collective" theory of risk considers a more general model than the one we have discussed. However, the generalisation is not along the lines indicated in the preceding paragraph. This theory drops the assumption we made in para 2.I that all premiums have been paid in advance. Instead it is assumed that premiums are paid continuously into the company's funds. This will in general make it necessary to take into account the probability of ruin within the period considered. It is well known that this leads to a family of ruin probabilities, far more complicated than the simple $p(S, F)$ which we have introduced above. Whether this generalisation is worth the heavy mathematics involved is an open question. Personally I think it of more interest to generalise the classical model to take into account all properties of the profit distribution.

\section{Measurable Utility}

3.1. The utility concept was the very corner stone of the economic theory developed in the last decades of the nineteenth century. However, many economists found it difficult to accept this concept which was impossible to measure, and difficult even to define in a precise manner. It was therefore considered as a major advance when Pareto showed that one could do without utility, and derive all the results of classical economics from the theory of indifference curves.

However, classical theory was not very successful when it came to analysing the uncertainty element in economics. When the first real break-through was made in this field by Von Neumann and Morgenstern (6), it appeared that utility was indispensable after all.

3.2. The authors of "Theory of Games" showed that utility could be defined in a rigorous manner, and that this utility concept was "measurable" in the sense that it was determined up to a linear transformation. They derived this result from a few axioms which essentially are topological in nature. The necessary axioms have later been given in several different forms, in order to make the basic assumptions clearer and more acceptable. However, the way to a desired theorem will in general become longer and more complicated when one takes simpler and more basic axioms as starting point. The reformulation of the axioms has therefore not encouraged 
many economists - or actuaries - to make full use of the possibilities of mathematical manipulations which are open, once utility is assumed measurable.

3.3 The few economists who have tried to apply this utility concept to "practical" problems, have approached their task with extreme suspicion. They usually have, like for instance Markowitz (5), gone through the axioms, one by one, in order to satisfy themselves that the axioms can be justified in the particular economic situation which they want to study. I have taken this approach myself in a previous paper (3), where incidentally, axiom 4 is given in a meaningless form. However, such an elaborate procedure can usually be avoided. All economic analysis is based on a number of assumptions, and in most cases we will find that these assumptions either imply, or are closely related to the axioms which lead to measurable utility.

3.4. In insurance a basic assumption is that there will always exist a unique amount of money which is the lowest premium at which a company will undertake to pay a claim with a known probability distribution. This assumption establishes an equivalence between certain and uncertain events. The crucial, and most debated point in the utility theory of Von Neumann and Morgenstern is the existence of an equivalence of this kind. Once it is taken for granted, as it seems natural to do in insurance, the measurable utility follows as an almost trivial consequence.

3.5. The basic assumption referred to can be formulated as: Axiom I. An insurance company has a complete preference ordering over the set of all probability distributions so that:

(i) To any probability distribution $F(x)$ there corresponds one, and only one number $R$, so that the two probability distributions $F(x)$ and $\varepsilon(x-R)$ are equivalent.

(ii) $\varepsilon\left(x-R_{1}\right)$ is preferred to $\varepsilon\left(x-R_{2}\right)$ if, and only if $R_{1}>R_{2}$.

Here $\varepsilon(x)$ is the degenerate probability distribution defined by

$$
\begin{array}{ll}
\varepsilon(x)=0 & \text { for } x<0 \\
\varepsilon(x)=\mathrm{I} & \text { for } 0 \leq x
\end{array}
$$


To each probability distribution $F(x)$ we can now associate a utility indicator, i.e. a number $U(F(x))$, such that:

(i) $U(F(x))=U(G(x))$

it $F(x)$ and $G(x)$ are equivalent.

(ii) $U(F(x))>U(G(x))$

if $F(x)$ is preferred to $G(x)$.

3.6. The utility indicator $U(F(x))$ is indeterminate in the sense that $\varphi(U)$, where $\varphi(y)$ is an arbitrary increasing function of $y$, can serve as utility indicator for the preference ordering. To get a more determinate indicator, one must make some assumptions that the company is "rational" or "consistent" in its preferences. We will express this as:

Axiom 2. If the probability distributions $F_{1}(x)$ and $F_{2}(x)$ are equivalent, the probability distributions $\alpha F_{1}(x)+(\mathbf{I}-\alpha) G(x)$ and $\alpha F_{2}(x)+(\mathrm{I}-\alpha) G(x)$ will also be equivalent.

Here $G(x)$ is an arbitrary probability distribution, and $\alpha$ is a real number $0 \leq \alpha \leq \mathrm{I}$.

3.7. From Axiom 2 it follows that

$$
U\left(\alpha F_{1}(x)+(\mathrm{I}-\alpha) G(x)\right)=U\left(\alpha F_{2}(x)+(\mathrm{I}-\alpha) G(x)\right)
$$

or if we take $G(x)=F_{2}(x)$

$$
U\left(\alpha F_{1}(x)+(\mathrm{I}-\alpha) F_{2}(x)\right)=U\left(F_{2}(x)\right)
$$

Since the left-hand side must be independent of $\alpha$, it follows that the utility indicator must be of the form

$$
U\left(\alpha F_{1}(x)+(\mathrm{I}-\alpha) F_{2}(x)\right)=\alpha U\left(F_{1}(x)\right)+(\mathrm{I}-\alpha) U\left(F_{2}(x)\right)
$$

For an arbitrary probability distribution we can write

$$
F(x)=\int_{-\infty}^{+\infty} \varepsilon(x-y) d F(y)
$$

Hence we have in general

$$
U(F(x))=\int_{-\infty}^{+\infty} U(\varepsilon(x-y)) d F(y)
$$

This is the Bernoullian hypothesis, which gives the utility of a probability distribution (or a risk situation) as a weighed sum of the utilities attached to degenerate distributions, i.e. certain events. 
3.8. It is convenient to write

$$
u(y)=U(\varepsilon(x-y))
$$

$u(y)$ is then the utility attached to an amount of money $y$, payable with probability I, i.e. $u(y)$ can be interpreted as the "utility of money", which plays an important part in classical economic theory.

We can then write

$$
U(F(x))=\int_{-\infty}^{+\infty} u(x) d F(x)
$$

It is easily verified that the preference ordering determines $u(x)$ only up to a linear transformation, i.e. $u(x)$ and $A u(x)+B$, where $A$ and $B$ are constants, will represent the same preference ordering.

3.9. The "utility of money" can best be considered as an operator which establishes an ordering over the set of profit distributions. To give it a more direct interpretation implies that we attach a meaning to statements such as: "An increase in profits from $\$ 0.5$ million to $\$$ I million is $50 \%$ better than an increase from $\$ 2$ millions to $\$ 3$ millions". This is not an attractive starting point for a rational theory of insurance, although something of this nature obviously is implied in the two axioms.

\section{Application to Reinsurance}

4.1. We will now consider an insurance company which has a preference ordering over the set of all profit distributions. We will assume that this preference ordering satisfies the two axioms in section 3 , and that it can be represented by a "utility of money" $u(x)$.

The utility which the company attaches to the risk situation $(S, F(x))$ is then given by

$$
U(S, F(x))=\int_{0}^{\infty} u(S-x) d F(x)
$$

The reinsurance problem formulated in para 2.3 can now be generalised to that of maximising this expression over the set of risk situations which the company can reach by reinsurance ar- 
rangements. This procedure will obviously take into account all properties of $F(x)$ as we required in para 2.5 .

4.2. The previous papers (I), (2) and (3) already referred to, contain several examples of such maximising problems. We shall therefore in the present paper only consider one simple example.

We assume that a company in the risk situation $(S, F(x))$ wants to reinsure a quota $k$ of its portfolio. For this reinsurance cover the company has to pay the net premium $k P$ of the ceded quota, plus a loading $\lambda k P$.

The optimal quota will then evidently be the value of $k$ which maximises the expression

$$
\int_{0}^{\infty} u(S-(\mathrm{I}+\lambda) k P-(\mathrm{I}-k) x) d F(x)
$$

where $P$ is the net premium of the whole portfolio, i.e.

$$
P=\int_{0}^{\infty} x d F(x)
$$

It is obvious that this maximising problem can be solved when $F(x)$ and $u(x)$ are given.

4.3. We will now assume that

and

$$
F(x)=\mathrm{I}-e^{-x}
$$

$$
u(x)=-a x^{2}+x+b
$$

This form of $u(x)$ has been studied in some detail in previous papers. It seems to give acceptable results, provided that $a$ is positive, and so small that $u(x)$ is increasing over the whole range considered, i.e. $2 a S<$ I. $a$ can obviously be taken as a measure of the company's "risk aversion". If $a=0$, the company will be indifferent to risk. The utility attached to any risk situation will then be proportional to expected profit.

It is easy to verify that the value of $k$ which maximises the company's utility, is given by

$$
k=\frac{2 a(\mathrm{I}-\lambda)-\lambda(\mathrm{I}-2 a S)}{2 a\left(\mathrm{I}+\lambda^{2}\right)}
$$


4.4. To give a numerical illustration, we will take

$$
\begin{aligned}
& a=\frac{1}{3}, \quad b=0 . \mathrm{I} 35 \\
& S=\mathrm{I} .2, \quad \lambda=0 . \mathrm{I}
\end{aligned}
$$

We find that in this case the company's utility is maximised for $k=0.86$. The table below gives the utility for different values of $k$. That utility is zero in the initial situation, i.e. for $k=0$, has of course no significance, since the origin and the unit of measurement for the utility scale can be chosen arbitrarily. The last two columns of the table give expected profit and the probability of ruin, i.e. the probability that the company shall be insolvent at the end of the period considered.

Quota Share Reinsurance

\begin{tabular}{l|l|l|l}
\hline$k$ & Utility & Expected Profit & $\begin{array}{c}\text { Probability } \\
\text { of ruin }\end{array}$ \\
\hline 0 & 0 & 0.20 & 0.3012 \\
0.1 & 0.056 & 0.19 & 0.2982 \\
0.2 & 0.101 & 0.18 & 0.2923 \\
0.3 & 0.142 & 0.17 & 0.2865 \\
0.4 & 0.174 & 0.16 & 0.2808 \\
0.5 & 0.195 & 0.15 & 0.2725 \\
0.6 & 0.216 & 0.14 & 0.2645 \\
0.7 & 0.230 & 0.13 & 0.2393 \\
0.8 & 0.237 & 0.12 & 0.2019 \\
0.86 & 0.240 & 0.115 & 0.1791 \\
0.9 & 0.238 & 0.11 & 0.1225 \\
1.0 & 0.231 & 0.10 & 0 \\
\hline
\end{tabular}

\section{Conclusion}

5.1. The example in section 4 shows that it is relatively simple to determine the optimal reinsurance arrangement if we assume that the utility of money to an insurance company can be represented by a continuous, increasing function. However, the existence of such a function follows from the innocent looking axioms in section 3 , and it seems difficult to argue that well managed insurance companies should violate these axioms.

5.2. The validity of the axioms leading to the Bernoullian theorem has been questioned by several authors, on different 
grounds. The most important criticism has been directed against the substitution principle implicit in the axioms. It is easy to show by examples that this principle does not seem to be generally applicable. It is doubtful, to say the least, that there exist certain public honours (or disgrace) which are equivalent to a fifty-fifty chance of either being hanged or receiving one million dollars. One of Walter Scott's heros ("Waverly") is willing to make a toss for a coronet or a coffin, but we cannot assume, as the axioms imply, that any person would be willing to play such a game if the probabilities were suitably adjusted. It seems, however, that this general criticism does not concern the applicability of the Bernoullian hypothesis to insurance where the only events considered are payment of different amounts of money.

5.3. Another group of critics has contested the relevance of probabilities to economic decisions made under uncertainty. The most eloquent member of this group is probably Shackle (7). Shackle maintains that a businessman will not consider all possible outcomes which may follow a decision he is about to make. Instead he will pay attention only to two focal values. These values are the worst and the best outcome which the businessman considers so likely that they must be taken into account. Other outcomes, which are "out of focus" are ignored.

It seems almost preposterous to maintain that companies ignore probabilities when they take decisions concerning reinsurance. It should, however, be noted that Shackle does not consider his theory as normative in the sense that it states how rational businessmen should take decisions. All he claims is that his theory describes, or explains how businessmen actually reach their decisions. This might apply to insurance companies, since as we have seen, the theory of reinsurance has almost exclusively considered the two "focal values", ruin and expected profit.

5.4. Shackle's views are well expressed by Giraudoux's Belle Hélène ("La guerre de Troie n'aura pas lieu"):

Hélène: Ne me brusquez pas. Je choisis les événements comme je choisis les objects et les hommes. Je choisis ceux qui ne sont pas pour moi des ombres. Je choisis ceux que je vois. 
Hector: Voici ta concurrante, Cassandre. Celle-là aussi lit l'avenir.

Hélène: Je ne lis pas l'avenir. Mais dans cet avenir, je vois des scènes colorées, d'autres ternes. Jusqu'ici ce sont toujours les scènes colorées qui ont eu lieu.

If Cassandra should look for a job, any insurance company could profitably employ her. As she presumably is not available, companies seem to have engaged, as a substitute, la belle Hélène, who can only see the dreadful possibility of ruin and the rosy situ. ation where everything goes according to mathematical expectation. She may have her attractions, but one may ask if she is the right person to take charge of the reinsurance arrangements.

\section{REFERENCES}

(I) Borch, Karl: "An Attempt to Determine the Optimum Amount of Stop Loss Reinsurance", Transactions of the XVIth International Congress of Actuaries, Vol. 2, pp. 597-6Io.

(2) BORCH, KARL: "Reciprocal Reinsurance Treaties", The Astin Bulletin, Vol. I, pp. I70-I9I.

(3) Borch, KarL: "Reciprocal Reinsurance Treaties seen as a Two-person Co-operative Game", Skandinavisk Aktuarietidskrift, I96o, pp. 29-58.

(4) Guldberg, Alf: "Zur Theorie des Risikos", Reports of the Sixth International Congress of Actuaries, Vol. I, pp. 753-764.

(5) Markowitz, Harry: Portfolio Selection, John Wiley \& Sons, I959.

(6) Neumann, J. von and O. Morgenstern: Theory of Games and Economic Behavior, Princeton 1944.

(7) Shackle, G. L. S.: Expectation in Economics, Cambridge 1949. 